\title{
A Study on the Reliability of an On-Site Oral Fluid Drug Test in a Recreational Context
}

\author{
Stefano Gentili, ${ }^{1}$ Renata Solimini, ${ }^{1}$ Roberta Tittarelli, ${ }^{2}$ \\ Giulio Mannocchi, ${ }^{2}$ and Francesco Paolo Busardo ${ }^{2}$ \\ ${ }^{1}$ Drug Abuse and Doping Unit, Department of Therapeutic Research and Medicines Evaluation, \\ Istituto Superiore di Sanità, Rome, Italy \\ ${ }^{2}$ Unit of Forensic Toxicology (UoFT), Department of Anatomical, Histological, Forensic and Orthopedic Sciences, \\ Sapienza University of Rome, Rome, Italy
}

Correspondence should be addressed to Francesco Paolo Busardò; fra.busardo@libero.it

Received 7 April 2016; Revised 15 July 2016; Accepted 26 July 2016

Academic Editor: Antony C. Calokerinos

Copyright (c) 2016 Stefano Gentili et al. This is an open access article distributed under the Creative Commons Attribution License, which permits unrestricted use, distribution, and reproduction in any medium, provided the original work is properly cited.

The reliability of DrugWipe 5A on site test for principal drugs of abuse (cannabis, amphetamines, cocaine, and opiates) detection in oral fluid was assessed by comparing the on-site results with headspace solid-phase microextraction (HS-SPME) gas chromatography-mass spectrometry (GC-MS) analysis on samples extracted by the device collection pad. Oral fluid samples were collected at recreational settings (e.g., discos, pubs, and music bars) of Rome metropolitan area. Eighty-three club goers underwent the on-site drug screening test with one device. Independently from the result obtained, a second device was used just to collect another oral fluid sample subsequently extracted and analyzed in the laboratory following HS-SPME procedure, gas chromatographic separation by a capillary column, and MS detection by electron impact ionization. DrugWipe 5A on-site test showed 54 samples (65.1\%) positive to one or more drugs of abuse, whereas 75 samples $(90.4 \%)$ tested positive for one or more substances following GC-MS assay. Comparing the obtained results, the device showed sensitivity, specificity, and accuracy around $80 \%$ for amphetamines class. Sensitivity (67 and 50\%) was obtained for cocaine and opiates, while both sensitivity and accuracy were unsuccessful (29 and 53\%, resp.) for cannabis, underlying the limitation of the device for this latter drug class.

\section{Introduction}

There has been increasing interest regarding a variety of alternative biological matrices such as oral fluid, sweat, and hair in the last few years $[1,2]$. Specifically, oral fluid shows several advantages in the on-site screening for drug use. The collection is noninvasive and easy to perform; it can be achieved in privacy, under close supervision, thereby reducing any opportunity of sample adulteration [3].

Furthermore, oral fluid reflects blood-drug concentrations due to the correlation between kinetics of several drugs in the blood and oral fluid, suggesting recent drug use.

Recent data have demonstrated an improvement in some on-site drug testing to disclose current consumption of illicit drugs. This significant progress in the sample collection and the improved accuracy of analysis have determined a certain success of on-site tests on oral fluid [4-9].
Although international literature suggests that the manufacturers overstate the capabilities of on-site testing devices to detect drugs in oral fluids, a number of new on-site testing devices have been constantly developed [10-16].

These devices are being used in many countries to perform on-site testing on oral fluid controls in Driving Under the Influence of Drugs (DUID) [5, 7, 10, 11, 13, 15] and several recent publications demonstrate that oral fluid screening devices are becoming more robust and reliable $[12,17-20]$.

In Italy, since August 2010, the law has considered oral fluid as an alternative biological specimen for the determination of DUID. Specifically, the devices can be used for rapid on-site testing as a first screening [21].

Among the developed devices, DrugWipe ${ }^{\circledR}$ is an immunochromatographic test strip, based on the Frontline urine test strip from Boehringer Mannheim (F. Hoffmann-La 
Roche, Basel, Switzerland) [22]. A pink colour in the test window indicates the presence of the analyte to which the test is specifically addressed and different devices are needed for the detection of each class of drugs of abuse. A recent version of this device, DrugWipe 5A, can simultaneously reveal the presence of cannabis, amphetamine, methamphetamine, ecstasy, cocaine, and opiates in oral fluid of consumers. In detail, the device is divided into two parts with two different collection pads: one for opiates and cocaine and the other for amphetamines and cannabis.

Here is reported our experience with application of DrugWipe $5 \mathrm{~A}$ on-site oral fluid testing in recreational settings, subsequent oral fluid collection, and quantitative detection of opiates, cocaine, amphetamines, and cannabis during preventive actions carried out by a nongovernmental organization (NGO) against drug use in recreational settings (e.g., discos, pubs, and music bars) of Rome metropolitan area (Lazio, Italy).

The study's aim was to verify the reliability of DrugWipe $5 \mathrm{~A}$ device for an on-site drug screening and whether a second device could be used as a simple collector for a subsequent confirmatory chromatographic-mass spectrometric assay. Specifically, easy and low-cost solvent-free headspace solidphase microextraction and gas chromatography-mass spectrometry for drugs abuse (amphetamines, opiates, cocaine, and cannabinoids) in oral fluid directly collected by the device pad has been used. The method has been applied in real cases of 83 drivers stopped during roadside controls.

\section{Experimental}

2.1. Chemicals, Reagent, and Device. Codeine, morphine, 6monoacetylmorphine (6-MAM), codeine- $\mathrm{d}_{3}$, morphine- $\mathrm{d}_{3}$, 6-monoacetylmorphine- $\mathrm{d}_{3}$, amphetamine $(\mathrm{A})$, methamphetamine (MA), methylenedioxyamphetamine (MDA), methylenedioxymethamphetamine (MDMA), methylenedioxyethamphetamine (MDE), $N$-methyl-1-(1,3-benzodioxol-5-yl)-2butanamine (MBDB), ketamine, methadone, cocaine, cocaethylene, $\Delta$ 9-Tetrahydrocannabinol (THC), 3,4-methylenedioxypropylamphetamine (MDPA), cocaine- $\mathrm{d}_{3}\left(\mathrm{COC}-\mathrm{d}_{3}\right), \Delta 8$ Tetrahydrocannabinol $(\triangle 8 \mathrm{THC}), \mathrm{N}$-Methyl-N-(trimethylsilyl)trifluoroacetamide (MSTFA), N,O-bis(trimethylsilyl)trifluoroacetamide (BSTFA), and trimethylchlorosilane (TMCS) were purchased from Sigma Aldrich (Milan, Italy).

Ultrapure water was obtained from a Milli-Q Unit (Millipore, Bedford, MA, USA). Acetic anhydride, sodium hydroxide $(\mathrm{NaOH})$, hydrochloric acid $(\mathrm{HCl})$, sodium chloride $(\mathrm{NaCl})$, potassium carbonate $\left(\mathrm{K}_{2} \mathrm{CO}_{3}\right)$, and acetone of analytical grade were purchased from Carlo Erba (Milan, Italy).

A solid-phase microextraction SPME Holder (manual) assembly with a replaceable extraction fibre coated with $100 \mu \mathrm{m}$ polydimethylsiloxane (PDMS) and a 110 VAC block heater purchased from Sigma-Aldrich were used. DrugWipe $5 \mathrm{~A}$ devices were provided by Securetec (Brunnthal, Germany).
2.2. Subjects and Oral Fluid Testing with DrugWipe 5A. During preventive actions (January to March 2015) carried out by NGO in the five principal discos, pubs, and music bars of Roma metropolitan area, 83 young people were tested with the DrugWipe 5A oral fluid screening device obtained from Securetec (Brunnthal, Germany). The participants were informed on the purpose of sample collection, and they gave signed consent to the collection and subsequent anonymous analysis of their oral fluid.

NGO staff performed oral fluid screening tests by wiping the tongue of the drug users 5-10 times with the collection pad, as recommended by the manufacturing instructions. After the sampling, the collection pad was put into direct contact with the drug test strip. Drug test and validity results were visually read after 10 minutes. Two coloured lines, one in the upper control window and one in the lower test window, indicate a positive result. Cut-off values for different drug groups provided by the manufacturer were the following: amphetamines, $50 \mathrm{ng} / \mathrm{mL}$; methamphetamines, $25 \mathrm{ng} / \mathrm{mL}$; MDMA, $25 \mathrm{ng} / \mathrm{mL}$; cocaine, $30 \mathrm{ng} / \mathrm{mL}$; opiates, $10 \mathrm{ng} / \mathrm{mL}$; and cannabis, $30 \mathrm{ng} / \mathrm{mL}$.

Another oral fluid sample was collected using DrugWipe $5 \mathrm{~A}$ and the two collection pads were mailed to the analytical laboratory and stored at ambient temperature without any preservative until HS-SPME-GC-MS analysis was performed (for a maximum of 14 days).

In both cases of positive and negative results to the first screening test on oral fluid by DrugWipe $5 \mathrm{~A}$, a second sample was collected for chromatographic analysis.

2.3. Calibration Standards. Stock solutions of each analyte $(1 \mathrm{mg} / \mathrm{mL})$ were combined and diluted with methanol to set working calibrator solutions $(0.01,0.02,0.05,0.10,1.00$, and $2.00 \mu \mathrm{g} / \mathrm{mL}$ ). Working internal standard methanol solutions at $2 \mu \mathrm{g} / \mathrm{mL}$ were also prepared. Stock solutions were stored at $-20^{\circ} \mathrm{C}$ until use. Blank oral fluid samples were obtained by wiping the tongue of laboratory staff 5-10 times with the DrugWipe 5A test pad.

Oral fluid calibrations were prepared by spiking $5 \mu \mathrm{L}$ of working calibrator solutions and internal standard solutions directly onto the test pad area of the blank sample.

Quality control samples of $0.075 \mathrm{ng} / \mathrm{pad}$ (low control), $0.15 \mathrm{ng} / \mathrm{pad}$ (medium control), and $0.45 \mathrm{ng} / \mathrm{pad}$ (high control) for THC and $0.45 \mathrm{ng} / \mathrm{pad}$ (low control), $2.00 \mathrm{ng} / \mathrm{pad}$ (medium control), and $4.00 \mathrm{ng} / \mathrm{pad}$ (high control) for other drugs of abuse were prepared in the same oral fluid drugfree pad and stored until analysis. They were included in each analytical batch to check calibration, accuracy and precision, and stability of samples under storage conditions.

Although recently some authors claim the volume to be about $20 \mu \mathrm{L}$ [23], other authors reported that limited or unknown collection volume from the collection device might create a number of difficulties for the laboratory [24, 25]. For this reason, the concentration of the analytes was expressed in ng substance/pad.

2.4. Oral Fluid Analysis. Oral fluid samples collected by a second DrugWipe 5A device were analyzed by headspace 
solid-phase microextraction (HS-SPME) and gas chromatography-mass spectrometry (GC-MS) procedures according to Merola et al. [26] and Moller et al. [27]. In particular, although ketamine was not among the substances screened by DrugWipe, HS-SPME-GC-MS investigated it for information on current drug consumption.

For the analysis of opiates, the first pad was removed and extracted with $200 \mu \mathrm{L}$ methanol in a closed headspace vial $(2 \mathrm{~mL})$, containing internal standard solution $(5 \mu \mathrm{L}$ of $2 \mu \mathrm{g} / \mathrm{mL}$ codeine- $\mathrm{d}_{3}$, morphine- $\mathrm{d}_{3}$, and 6-monoacetylmorphine- $\mathrm{d}_{3}$ ). The sample was incubated for $60 \mathrm{~min}$ at $60^{\circ} \mathrm{C}$. The methanol extract was transferred to a $10 \mathrm{~mL}$ vial and dried under nitrogen flow, $10 \mu \mathrm{L}$ BSTFA $+1 \%$ TMCS were added, and the SPME needle was introduced into the vial and exposed to adsorption for $30 \mathrm{~min}$ at $125^{\circ} \mathrm{C}$. Finally, thermal desorption of the fibre was performed at $250^{\circ} \mathrm{C}$ for $3 \mathrm{~min}$ inside the GC.

For cocaine, ketamine, and amphetamines, the second pad was removed and extracted with $200 \mu \mathrm{L} 1 \mathrm{M} \mathrm{HCl}$ in a closed headspace vial $(20 \mathrm{~mL})$, containing internal standards ( $5 \mu \mathrm{L}$ of $2 \mu \mathrm{g} / \mathrm{mL}$ MDPA, COC-d ${ }_{3}$ MDPA, and $\Delta-8 \mathrm{THC}$ ). The sample was incubated for $60 \mathrm{~min}$ at $60^{\circ} \mathrm{C}$.

After cooling at room temperature, the extracted acid layer was transferred to another vial $(2 \mathrm{~mL})$ containing $200 \mathrm{mg} \mathrm{K} \mathrm{CO}_{3}$, the SPME needle was introduced, and the fibre was exposed to adsorption for $10 \mathrm{~min}$ at $90^{\circ} \mathrm{C} ; 5 \mu \mathrm{L}$ acetic anhydride was added, and the SPME needle was introduced into a second vial and exposed for $3 \mathrm{~min}$ at $90^{\circ}$. Thermal desorption was performed at $250^{\circ} \mathrm{C}$ for $3 \mathrm{~min}$ inside the GC.

For THC extraction, $1 \mathrm{~mL} \mathrm{NaOH} 1 \mathrm{M}$ and $0.5 \mathrm{~g} \mathrm{NaCl}$ were added to the vial containing the pad previously used; the SPME needle was introduced into the vial and exposed to adsorption for $30 \mathrm{~min}$ at $150^{\circ} \mathrm{C}$. For derivatization, $5 \mu \mathrm{L}$ of MSTFA was added and the fibre was exposed for $10 \mathrm{~min}$ at $90^{\circ} \mathrm{C}$. Thermal desorption was performed at $250^{\circ} \mathrm{C}$ for $3 \mathrm{~min}$ inside the GC.

2.5. GC-MS Analysis. A Gas Chromatography 6890 Plus and Mass Selective Detector 5973N (Hewlett-Packard, Palo Alto, CA, USA) equipped with a J\&W 19091S-101 HP-5MS Trace Analysis capillary column (5\% PH ME Siloxane; film thickness, $0.33 \mu \mathrm{m}$; length, $12.5 \mathrm{~m}$; column ID, $0.20 \mathrm{~mm}$ ) was used. The column temperature was initially held at $60^{\circ} \mathrm{C}$ for $2 \mathrm{~min}$ and then raised $20^{\circ} \mathrm{C} / \mathrm{min}$ to reach $250^{\circ} \mathrm{C}$ and finally held at $250^{\circ} \mathrm{C}$ for $5 \mathrm{~min}$. The temperature of the injection port, ion source, and transfer line was set at $250^{\circ} \mathrm{C}, 230^{\circ} \mathrm{C}$, and $280^{\circ} \mathrm{C}$, respectively. Thermal desorption was performed at $250^{\circ} \mathrm{C}$ for $3 \mathrm{~min}$ inside the gas chromatograph. Helium was used as carrier gas at a flow rate of $0.7 \mathrm{~mL} / \mathrm{min}$. The splitless injection mode was used. The mass spectrometer uses electron impact ionization. The mass spectra were collected by total ion chromatography. Identification criteria were based on retention time (RT) \pm 0.02 min with respect to the samein spiked oral fluid sample and on the relative abundance of the three confirming ions with respect to the target. Quantitative data were obtained by selected ion monitoring for each compound and for internal standards (IS). Monitored ions and RT for each compound are shown in Table 1.
TABLE 1: Monitored ions and retention time (RT) for drugs of abuse in oral fluid samples by HS-SPME-GC-MS.

\begin{tabular}{|c|c|c|}
\hline Compound & $\mathrm{RT}(\min )$ & $\begin{array}{c}\text { Ion } m / z \\
\text { (relative abundance) }\end{array}$ \\
\hline $\mathrm{A}$ & 9.32 & $86,91,118$ \\
\hline MA & 9.37 & $\mathbf{5 8}, 91,100$ \\
\hline MDA & 11.32 & $162,135,221$ \\
\hline Ketamine & 11.36 & $180,182,209$ \\
\hline MDMA & 11.75 & $58,100,162$ \\
\hline MDE & 11.96 & $72,114,162$ \\
\hline MBDB & 12.07 & $72,114,176$ \\
\hline $\operatorname{MDPA}(\mathrm{IS})^{* *}$ & 12.34 & $\mathbf{8 6}, 128,162$ \\
\hline Methadone & 13.03 & $72,91,294$ \\
\hline COC $-\mathrm{d}_{3}(\mathrm{IS})^{* *}$ & 13.48 & $85, \mathbf{1 8 5}, 306$ \\
\hline Cocaine & 13.50 & $82,182,303$ \\
\hline Cocaethylene & 13.96 & $196,272,317$ \\
\hline$\Delta 8 \mathrm{THC}(\mathrm{IS})^{* *}$ & 14.52 & $303,330,386$ \\
\hline$\triangle 9 \mathrm{THC}$ & 14.71 & $303,371,386$ \\
\hline Codeine & 16.95 & $178,196,371$ \\
\hline Codeine- $\mathrm{d}_{3}(\text { IS })^{* *}$ & 16.99 & 181, 199, 374 \\
\hline Morphine & 17.70 & $236,401,429$ \\
\hline Morphine- $\mathrm{d}_{3}(\mathrm{IS})^{* *}$ & 17.73 & $239,404,432$ \\
\hline 6-MAM & 18.17 & 340, 357, 399 \\
\hline MAM-d $_{3}(\mathrm{IS})^{* *}$ & 18.19 & $343,360,402$ \\
\hline
\end{tabular}

A, amphetamine; MA, methamphetamine; MDA, methylenedioxyamphetamine; MDMA, methylenedioxymethamphetamine; MDE, methylenedioxyethamphetamine; MBDB, N-methyl-1-(1,3-benzodioxol-5-yl)-2-butanamine; THC, $\triangle 9$-Tetrahydrocannabinol; MDPA, 3,4-methylenedioxypropylamphetamine; COC- $\mathrm{d}_{3}$, cocaine- $\mathrm{d}_{3}$; $\Delta 8 \mathrm{THC}, \Delta 8$-Tetrahydrocannabinol; 6-MAM, 6-monoacetylmorphine.

** IS: internal standard.

Quantifier ions are in bold.

2.6. GC-MS Method Validation. Validation protocol applied in the present study included linearity, limit of detection (LOD), limit of quantification (LOQ), precision, accuracy, and stability as reported elsewhere [28-30].

Linearity was determined by least-squares regression with $1 / x^{2}$ weighting of the following concentration: $0.05,0.1$, $0.25,0.50$, and $1.00 \mathrm{ng} / \mathrm{pad}$ for THC and $0.25,0.50,1.00,2.50$, and $5.00 \mathrm{ng} / \mathrm{pad}$ for the other analytes. Acceptable linearity was achieved when the coefficient of determination was at least 0.99 . The LOD and LOQ were evaluated with decreasing analyte concentrations in drug-spiked oral fluid samples. The LOD was defined as the lowest concentration with acceptable chromatography, the presence of all transitions with signalto-noise ratios of at least 3 , and a retention time within $\pm 0.2 \mathrm{~min}$ of the average retention time of the calibrator. LOQ was the lowest concentration that met LOD criteria and a signal-to-noise ratio of at least 10 .

Precision, accuracy, and analytical recovery were calculated from five different daily replicates for five different days of $0.075,0.15$, and $0.45 \mathrm{ng} / \mathrm{pad}$ for THC and $0.45,2.00$, and $4.00 \mathrm{ng} / \mathrm{pad}$ for other drugs of abuse. 
TABLE 2: Linearity of the HS-SPME-GC-MS procedure for compounds under investigation.

\begin{tabular}{lcccccc}
\hline Compounds & Slope & Intercept & $R^{2}$ & LOD (ng/pad) & LOQ (ng/pad) & Analytical recovery (\%) \\
\hline A & 0.64 & 0.07 & 0.995 & 0.37 & 1.11 & $\mathbf{1 0 0 . 8}$ \\
MA & 2.08 & 0.20 & 0.990 & 0.68 & 0.04 & $\mathbf{9 9 . 2}$ \\
MDA & 1.93 & -0.16 & 0.988 & 0.60 & 2.19 & $\mathbf{8 8 . 8}$ \\
Ketamine & 6.47 & -1.16 & 0.990 & 0.73 & 1.02 & $\mathbf{8 4 . 4}$ \\
MDMA & 5.57 & 0.86 & 0.996 & 0.34 & 0.78 & $\mathbf{1 0 0 . 8}$ \\
MDE & 5.73 & 0.14 & 0.998 & 0.26 & 0.33 & $\mathbf{1 0 3 . 2}$ \\
MBDB & 8.34 & 0.77 & 0.999 & 0.11 & 1.05 & $\mathbf{9 8 . 8}$ \\
Methadone & 9.74 & -1.46 & 0.990 & 0.71 & 1.53 & $\mathbf{8 5 . 5}$ \\
Cocaine & 6.18 & 0.05 & 0.996 & 0.35 & 0.18 & $\mathbf{1 0 7 . 6}$ \\
Cocaethylene & 2.01 & -0.42 & 0.992 & 0.51 & 0.18 & $\mathbf{9 0 . 4}$ \\
THC & 10.52 & 0.03 & 0.990 & 0.06 & 1.29 & $\mathbf{1 0 2 . 0}$ \\
Codeine & 4.73 & 0.63 & 0.996 & 0.06 & 0.43 & $\mathbf{9 6 . 0}$ \\
Morphine & 7.32 & 2.05 & 0.995 & 0.993 & 0.39 & $\mathbf{9 6 . 4}$ \\
6-MAM & 9.52 & 3.74 & & 0.993 & $\mathbf{1 0 5 . 6}$ \\
\hline
\end{tabular}

A, amphetamine; MA, methamphetamine; MDA, methylenedioxyamphetamine; MDMA, methylenedioxymethamphetamine; MDE, methylenedioxyethamphetamine; MBDB, $N$-methyl-1-(1,3-benzodioxol-5-yl)-2-butanamine; THC, $\Delta$ 9-Tetrahydrocannabinol; 6-MAM, 6-monoacetylmorphine.

Stability of analytes in the device pad was tested in triplicate at $0.50 \mathrm{ng} / \mathrm{pad}$ for THC and $5.00 \mathrm{ng} / \mathrm{pad}$ for other drugs of abuse left in the dark at room temperature for 7 and 14 days and then analyzed by HS-SPME-GC-MS.

2.7. Interpretation of the DrugWipe 5A Results. The evaluation of the results is based on classification into the following categories: true positive (TP), cases with a positive DrugWipe $5 \mathrm{~A}$ test result and a positive HS-SPME-GC-MS analysis result; false positive (FP), cases with a positive DrugWipe 5A test result and a negative GC-MS analysis result; true negative (TN), cases with a negative DrugWipe 5A test result and a negative GC-MS analysis result; false negative (FN), cases with a negative DrugWipe $5 \mathrm{~A}$ test result and a positive HSSPME-GC-MS analysis result.

Taking into consideration the above classification, sensitivity, specificity, and accuracy of the DrugWipe 5A oral fluid were calculated as follows. Sensitivity $=(\mathrm{TP} / \mathrm{TP}+\mathrm{FN} * 100)$. Specificity $=(\mathrm{TN} / \mathrm{TN}+\mathrm{FP} * 100)$. Accuracy $=(\mathrm{TP}+$ $\mathrm{TN} /$ number of tests) $[12,15]$.

\section{Results and Discussion}

3.1. Validation Results. Linear calibration curves were obtained for the compounds under investigation with correlation coefficients $\left(R^{2}\right)$ of at least 0.99 in all cases and LODs and LOQs values adequate for the purpose of the present study (Table 2).

Intraday and interday precision and accuracy of the analytes under investigation satisfactorily met the internationally established acceptance criteria and were always better than $15 \%$ (Table 3 ) and recovery ranged from $84.4 \%$ to $107.6 \%$ for the different compounds (Table 2).

With respect to stability test (Table 4), in samples stored in the dark, at room temperature, a maximum decrease of about
$15 \%$ initial concentration was observed for amphetamines, cocaine, and opiates after 14 days. Conversely, in case of THC, a decrease of $50 \%$ initial concentration was already observed after seven days and it remained stable at the same percentage after fourteen days. This is in agreement with Crouch's study on the effects of the oral fluid collection device on THC concentration and on its stability [24]. For instance, apart from THC instability, the device pad resulted to be a reliable tool for oral fluid collection, which could be mailed and stored at ambient temperature for a maximum of 14 days.

3.2. Samples Analysis. In order to demonstrate the usefulness of the device DrugWipe 5A, the results obtained by the device were compared to the ones obtained by HS-SPME-GC-MS in eighty-three clubs goers. In case of HS-SPME-GC-MS, only substances detected by this assay were reported in Table 5 .

The results of DrugWipe $5 \mathrm{~A}$ analysis showed that 54 samples $(65.1 \%)$ were positive to one or more substances: 8 were found to be positive to cannabis, 16 were found to be positive to amphetamines, and 8 were found to be positive to cocaine. Eight samples were positive to amphetamines and THC, 5 samples were positive to both amphetamines and cocaine, 2 samples were positive to THC and opiates, 3 samples were positive to cocaine and opiates, 1 sample was positive to amphetamines and opiates, and 3 samples were positive to amphetamines, cocaine, and opiates.

In the HS-SPME-GC-MS analysis, 75 samples (90.4\%) were positive for one or more substances: 35 were polydrug users, 21 were positive only for THC (ranged concentration: $<$ LOQ-11.82 ng/pad), 7 were positive for MDMA (ranged concentration: <LOQ-184.08 ng/pad), 8 were positive for cocaine (ranged concentration: <LOQ $-1398.05 \mathrm{ng} / \mathrm{pad}$ ), and 4 were positive for ketamine (ranged concentration: $<$ LOQ$9.09 \mathrm{ng} / \mathrm{pad})$, even if this substance was not included in DrugWipe screening. 


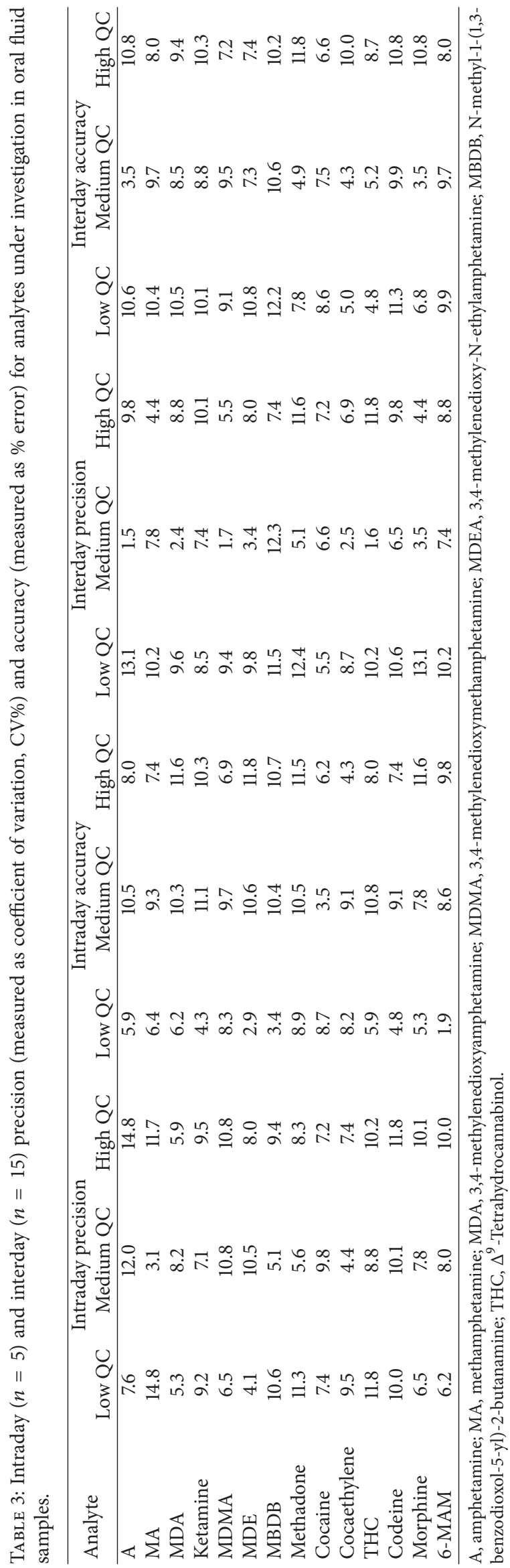


TABLE 4: Stability results at room temperature after 7-day and 14-day test.

\begin{tabular}{lcc}
\hline Analyte & 7-day test (\%) & 14-day test (\%) \\
\hline A & 96.0 & 85.0 \\
MA & 95.2 & 84.8 \\
MDA & 95.0 & 85.3 \\
Ketamine & 97.9 & 88.9 \\
MDMA & 96.0 & 85.1 \\
MDE & 95.6 & 84.9 \\
MBDB & 95.9 & 84.9 \\
Methadone & 99.7 & 88.9 \\
Cocaine & 99.9 & 86.1 \\
Cocaethylene & 98.5 & 85.1 \\
THC & 51.0 & 50.0 \\
Codeine & 98.5 & 89.1 \\
Morphine & 98.0 & 89.0 \\
6-MAM & 97.9 & 88.7 \\
\hline
\end{tabular}

A, amphetamine; MA, methamphetamine; MDA, 3,4-methylenedioxyamphetamine; MDMA, 3,4-methylenedioxymethamphetamine; MDEA, 3,4methylenedioxy-N-ethylamphetamine; MBDB, N-methyl-1-(1,3-benzodioxol-5-yl)-2-butanamine; THC, $\Delta^{9}$-Tetrahydrocannabinol.

DrugWipe 5A performance data (true positive, true negative, false positive, and false negative results) reported in Table 6 compared the device results with those obtained by HS-SPME-GC-MS and showed sensitivity, specificity, and accuracy of the device with respect to the different drug class.

The comparison between on-site and laboratory results confirmed the different reliability for each class of substances, as already reported in the literature [31].

From the obtained results, it can be said that the device performed quite well in detecting the amphetamines class, with sensitivity, specificity, and accuracy around $80 \%$ value.

The second best results were obtained in case of cocaine which showed good specificity and accuracy but worse sensitivity. In this concern, previous studies demonstrated that cocaine was predominantly found in oral fluid with respect to its principal metabolite benzoylecgonine, present in very low concentrations in this biological matrix $[3,9]$. Furthermore, recently, it has been demonstrated that oral fluid concentration of benzoylecgonine and the relationship with cocaine are time dependent, unless cocaine is intravenously administered [32]. Since benzoylecgonine extraction by HS-SPME and detection would have presented a great analytical difficulty due to its polar nature, this metabolite was not considered in this study. Indeed, for the reported reasons, its detection would not have increased the number of samples positive to cocaine.

In case of opiates, an even poorer sensitivity value was calculated. The low prevalence for opiates in the studied group of drivers did not allow a proper evaluation of the performances of DrugWipe 5A for these substances.

Finally, in agreement with previous observations $[13,16]$, our results highlight the unsuccessful detection of THC by DrugWipe 5A device for oral fluid.
Observations by NGO staff and some laboratory test simulations have confirmed that the line test for cannabis is usually very weak and delayed [25]. This difficulty in interpreting the results may give rise to a high number of false negatives.

The comparison between device cut-offs with HS-SPMEGC-MS results confirms the high specificity (always $>80 \%$ ) for all class of substances and the poor sensitive value for opiates (about 67\%) and THC (about 30\%). On the other side, we observed an increase of sensitivity of both amphetamines (about 92\%) and cocaine (about 80\%).

Outside the principal aim of the study, our results evidenced a nonnegligible $20.5 \%$ of our clubs goers consuming ketamine. To the best of our knowledge, this is the first time the objective assessment of the consumption of this drug has been performed in oral fluid samples from a population of Italian disco goers. Significant limitation of on-site oral fluid test devices is that they cannot usually detect increasing number of new psychoactive drugs. Ketamine is only one of them. This is an issue that should be taken into account, especially when the device is applied at recreational settings, where the use of new drugs may be likely. It can be underlined that study limitation could lie in the fact that HS-SPME-GC-MS assay was not carried out in real oral fluid samples but precisely on extracts of collection pad. Nevertheless, this occurrence allowed a direct comparison of the immunochromatographic screening test and a confirmatory gas chromatographicmass spectrometric assay on the same collected substrate. In addition, only eighty-three samples have been analyzed which cannot be conclusive but can be an eye opener on the reliability of this simple and easily applicable on-site test device for oral fluid drug testing.

\section{Conclusions}

From the results obtained in the present study, DrugWipe 5A device has been shown to be a practical, easy way of sampling and a non-time-consuming procedure for screening drug of abuse testing in oral fluid. The device has proven to be not sensitive and accurate enough for cannabis but acceptable for other drugs of abuse. Although oral fluid may be a useful matrix for on-site testing of drugged drivers, it is evident that it still shows a lack of sensitivity and, to ensure adequate reliability, GC-MS or LC-MS confirmation of on-site oral fluid screening tests remains necessary, due to the presence of a significant number of false negative and false positive results, even when using the commercial kit with the best performance.

\section{Competing Interests}

The authors declare that there are no competing interests.

\section{Acknowledgments}

The authors would like to thank Michele Sciotti, Simonetta di Carlo, Antonella Bacosi, Adele Minutillo, and Paolo Berretta for technical assistance. 


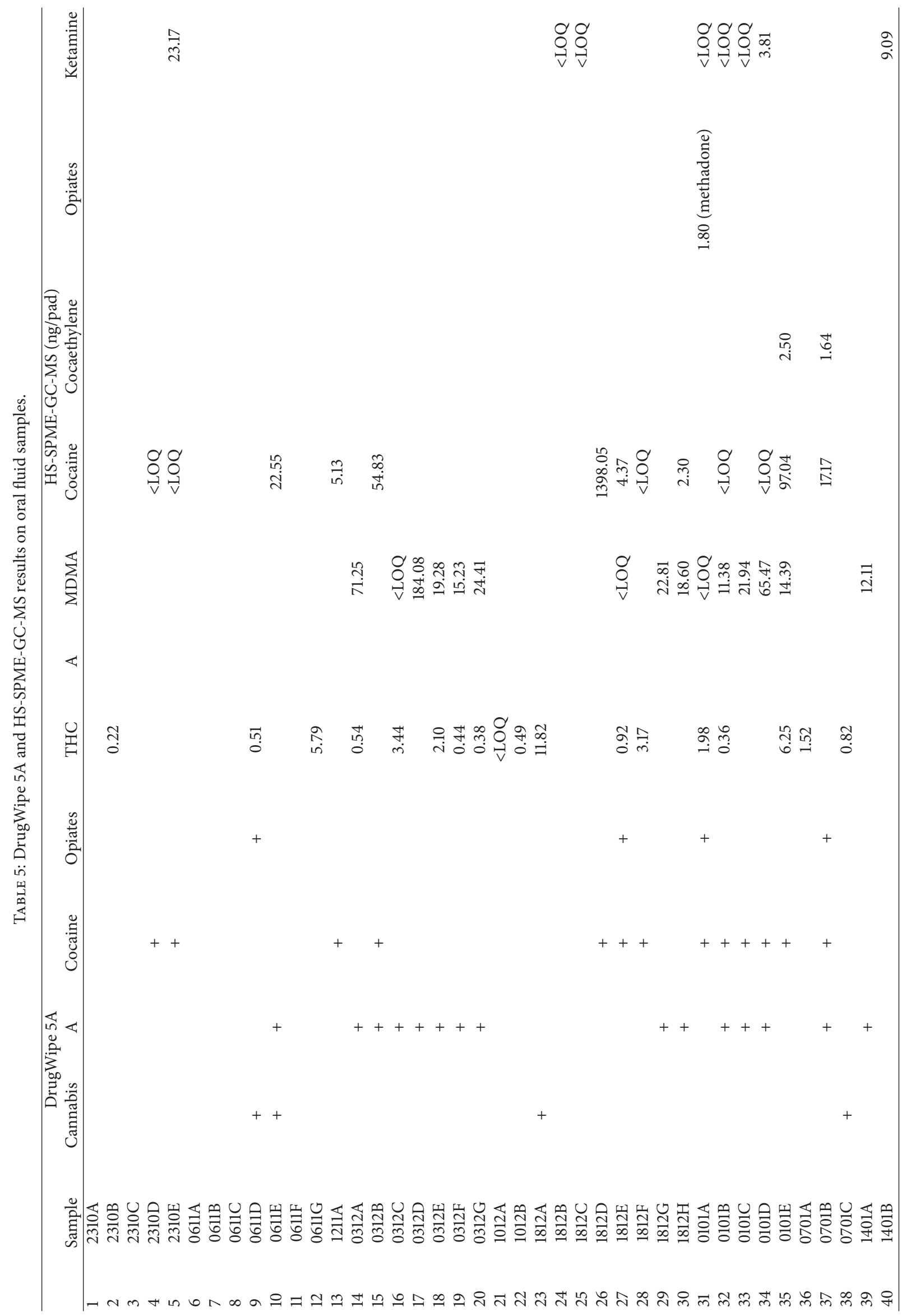




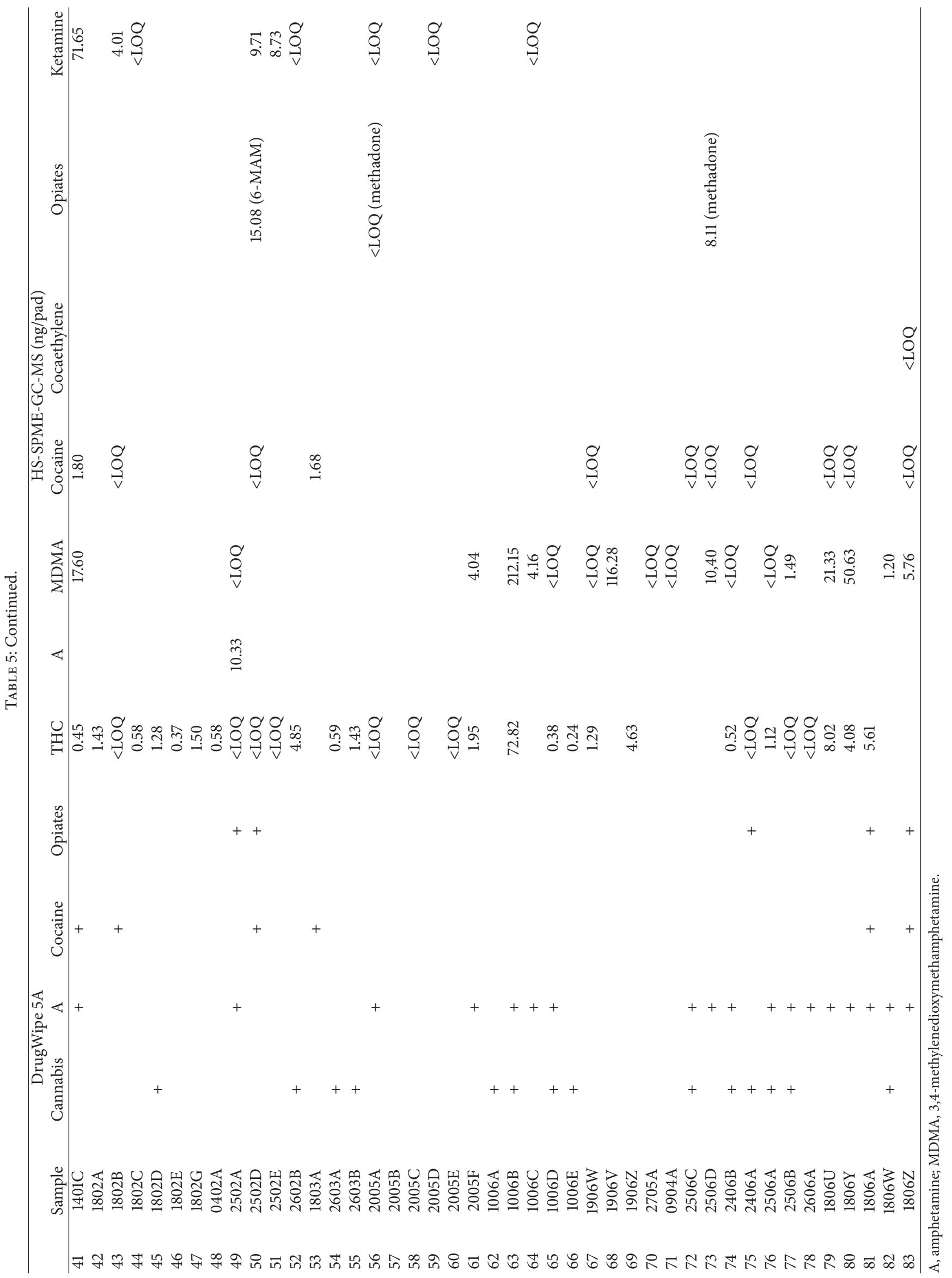


TABLE 6: Performance data of DrugWipe 5A in comparison with HSSPME-GC-MS results.

\begin{tabular}{lcccc}
\hline & Cannabis & Amphetamines & Cocaine & Opiates \\
\hline TP & 14 & 26 & 16 & 2 \\
FP & 4 & 7 & 3 & 7 \\
TN & 30 & 43 & 56 & 72 \\
FN & 35 & 7 & 8 & 2 \\
\hline Number of tests & 83 & 83 & 83 & 83 \\
\hline Sensitivity (\%) & 29 & 79 & 67 & 50 \\
Specificity (\%) & 88 & 86 & 95 & 91 \\
Accuracy (\%) & 53 & 83 & 87 & 89 \\
\hline
\end{tabular}

$\mathrm{TP}$, true positive; $\mathrm{FP}$, false positive; $\mathrm{TN}$, true negative; $\mathrm{FN}$, false negative.

\section{References}

[1] S. M. R. Wille, M. R. Baumgartner, V. Di Fazio, N. Samyn, and T. Kraemer, "Trends in drug testing in oral fluid and hair as alternative matrices," Bioanalysis, vol. 6, no. 17, pp. 2193-2209, 2014.

[2] S. Pichini, I. Altieri, P. Zuccaro, and R. Pacifici, "Drug monitoring in nonconventional biological fluids and matrices," Clinical Pharmacokinetics, vol. 30, no. 3, pp. 211-228, 1996.

[3] M. Pujadas, S. Pichini, E. Civit, E. Santamariña, K. Perez, and R. de la Torre, "A simple and reliable procedure for the determination of psychoactive drugs in oral fluid by gas chromatographymass spectrometry," Journal of Pharmaceutical and Biomedical Analysis, vol. 44, no. 2, pp. 594-601, 2007.

[4] J. M. Walsh, R. Flegel, D. J. Crouch, L. Cangianelli, and J. Baudys, "An evaluation of rapid point-of-collection oral fluid drug-testing devices," Journal of Analytical Toxicology, vol. 27, no. 7, pp. 429-439, 2003.

[5] S. Steinmeyer, H. Ohr, H. J. Maurer, and M. R. Moeller, "Practical aspects of roadside tests for administrative traffic offences in Germany," Forensic Science International, vol. 121, no. 1-2, pp. 33-36, 2001.

[6] T. Biermann, B. Schwarze, B. Zedler, and P. Betz, "On-site testing of illicit drugs: The use of the drug-testing device 'Toxiquick ${ }^{\circledR ”}$ '” Forensic Science International, vol. 143, no. 1, pp. 21-25, 2004.

[7] P. Kintz, V. Cirimele, F. Muhlmann, and B. Ludes, "Drug tests on 198 drivers involved in an accident," Presse Medicale, vol. 29, no. 23, pp. 1275-1278, 2000.

[8] E. Gallardo, M. Barroso, and J. A. Queiroz, "Current technologies and considerations for drug bioanalysis in oral fluid," Bioanalysis, vol. 1, no. 3, pp. 637-667, 2009.

[9] S. W. Toennes, S. Steinmeyer, H.-J. Maurer, M. R. Moeller, and G. F. Kauert, "Screening for drugs of abuse in oral fluidcorrelation of analysis results with serum in forensic cases," Journal of Analytical Toxicology, vol. 29, no. 1, pp. 22-27, 2005.

[10] D. J. Crouch, J. M. Walsh, L. Cangianelli, and O. Quintela, "Laboratory evaluation and field application of roadside oral fluid collectors and drug testing devices," Therapeutic Drug Monitoring, vol. 30, no. 2, pp. 188-195, 2008.

[11] J. M. Walsh, D. J. Crouch, J. P. Danaceau, L. Cangianelli, L. Liddicoat, and R. Adkins, "Evaluation of ten oral fluid point-of-collection drug-testing devices," Journal of Analytical Toxicology, vol. 31, no. 1, pp. 44-54, 2007.

[12] T. Blencowe, A. Pehrsson, P. Lillsunde et al., "An analytical evaluation of eight on-site oral fluid drug screening devices using laboratory confirmation results from oral fluid," Forensic Science International, vol. 208, no. 1-3, pp. 173-179, 2011.

[13] P. Kintz, W. Bernhard, M. Villain, M. Gasser, B. Aebi, and V. Cirimele, "Detection of cannabis use in drivers with the DrugWipe device and by GC-MS after intercept ${ }^{\circledR}$ device collection," Journal of Analytical Toxicology, vol. 29, no. 7, pp. 724-727, 2005.

[14] A.-S. Goessaert, K. Pil, J. Veramme, and A. Verstraete, "Analytical evaluation of a rapid on-site oral fluid drug test," Analytical and Bioanalytical Chemistry, vol. 396, no. 7, pp. 2461-2468, 2010.

[15] A. Pehrsson, T. Gunnar, C. Engblom, H. Seppa, A. Jama, and P. Lillsunde, "Roadside oral fluid testing: comparison of the results of drugwipe 5 and drugwipe benzodiazepines on-site tests with laboratory confirmation results of oral fluid and whole blood," Forensic Science International, vol. 175, no. 2-3, pp. 140-148, 2008.

[16] A. Pehrsson, T. Blencowe, K. Vimpari, K. Langel, C. Engblom, and P. Lillsunde, "An evaluation of on-site oral fluid drug screening devices DrugWipe ${ }^{\circledR} 5^{+}$and rapid STAT ${ }^{\circledR}$ using oral fluid for confirmation analysis," Journal of Analytical Toxicology, vol. 35, no. 4, pp. 211-218, 2011.

[17] N. A. Desrosiers, D. Lee, D. M. Schwope et al., "On-site test for cannabinoids in oral fluid," Clinical Chemistry, vol. 58, no. 10, pp. 1418-1425, 2012.

[18] S. Vanstechelman, C. Isalberti, T. Van der Linden, K. Pil, S.-A. Legrand, and A. G. Verstraete, "Analytical evaluation of four on-site oral fluid drug testing devices," Journal of Analytical Toxicology, vol. 36, no. 2, pp. 136-140, 2012.

[19] S. M. R. Wille, N. Samyn, M. D. M. Ramírez-Fernández, and G. De Boeck, "Evaluation of on-site oral fluid screening using drugwipe $-5^{+}{ }^{\circledR}$, rapidSTAT ${ }^{\circledR}$ and drug test $5000^{\circledR}$ for the detection of drugs of abuse in drivers," Forensic Science International, vol. 198, no. 1-3, pp. 2-6, 2010.

[20] S. Strano-Rossi, E. Castrignanò, L. Anzillotti et al., "Evaluation of four oral fluid devices (DDS ${ }^{\circledR}$, Drugtest $5000^{\circledR}$, Drugwipe $5+{ }^{\circledR}$ and RapidSTAT ${ }^{\circledR}$ ) for on-site monitoring drugged driving in comparison with UHPLC-MS/MS analysis," Forensic Science International, vol. 221, no. 1-3, pp. 70-76, 2012.

[21] Legge 29 luglio 2010, n. 120, Disposizioni in materia di sicurezza stradale, Art. 33: Modifiche agli articoli 186 e 187 e introduzione dell'articolo186-bis del decreto legislativo n. 285 del 1992.

[22] R. Wennig, M. R. Moeller, J. M. Haguenoer et al., "Development and evaluation of immunochromatographic rapid tests for screening of cannabinoids, cocaine, and opiates in urine," Journal of Analytical Toxicology, vol. 22, no. 2, pp. 148-155, 1998.

[23] S. M. R. Wille, V. Di Fazio, S. W. Toennes, J. H. P. van Wel, J. G. Ramaekers, and N. Samyn, "Evaluation of $\Delta^{9}$ tetrahydrocannabinol detection using DrugWipe $5 S^{\circledR}$ screening and oral fluid quantification after Quantisal ${ }^{\circledR}$ collection for roadside drug detection via a controlled study with chronic cannabis users," Drug Testing and Analysis, vol. 7, no. 3, pp. 178186, 2015.

[24] D. J. Crouch, "Oral fluid collection: the neglected variable in oral fluid testing," Forensic Science International, vol. 150, no. 2-3, pp. 165-173, 2005.

[25] P. Kintz, V. Cirimele, and B. Ludes, "Detection of cannabis in oral fluid (saliva) and forehead wipes (sweat) from impaired drivers," Journal of Analytical Toxicology, vol. 24, no. 7, pp. 557$561,2000$.

[26] G. Merola, S. Gentili, F. Tagliaro, and T. Macchia, "Determination of different recreational drugs in hair by HS-SPME and GC/MS," Analytical and Bioanalytical Chemistry, vol. 397, no. 7, pp. 2987-2995, 2010. 
[27] M. Moller, K. Aleksa, P. Walasek, T. Karaskov, and G. Koren, "Solid-phase microextraction for the detection of codeine, morphine and 6-monoacetylmorphine in human hair by gas chromatography-mass spectrometry," Forensic Science International, vol. 196, no. 1-3, pp. 64-69, 2010.

[28] R. Causon, "Validation of chromatographic methods in biomedical analysis. Viewpoint and discussion," Journal of Chromatography B: Biomedical Sciences and Applications, vol. 689, no. 1, pp. 175-180, 1997.

[29] M. Tompson, S. Eleison, and R. Wood, "Harmonized guidelines for single-laboratory validation of methods of analysis," Pure Applied Chemistry, vol. 74, no. 5, pp. 835-885, 2002.

[30] FDA Guidance for Industry Bioanalytical Method Validation, http://www.fda.gov/downloads/Drugs/Guidance/ucm070107 .pdf.

[31] ROSITA II Project: Evaluation of on-Site Saliva Drug Testing Devices in Washington State, http://www.rosita.org/.

[32] K. N. Ellefsen, M. Concheiro, S. Pirard, D. A. Gorelick, and M. A. Huestis, "Oral fluid cocaine and benzoylecgonine concentrations following controlled intravenous cocaine administration," Forensic Science International, vol. 260, pp. 95-101, 2016. 

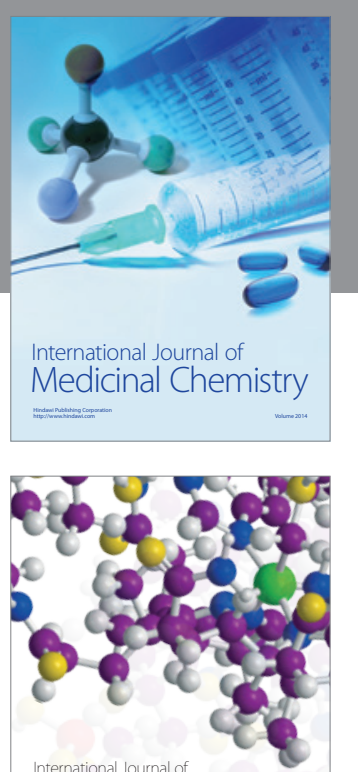

Carbohydrate Chemistry

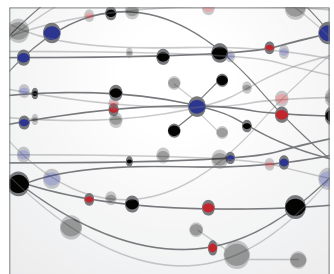

The Scientific World Journal
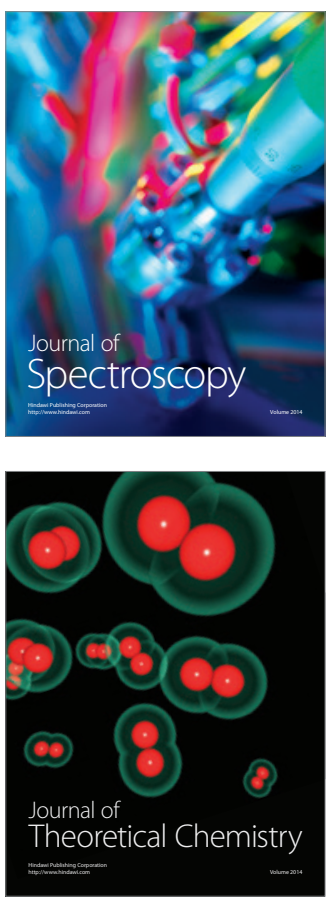
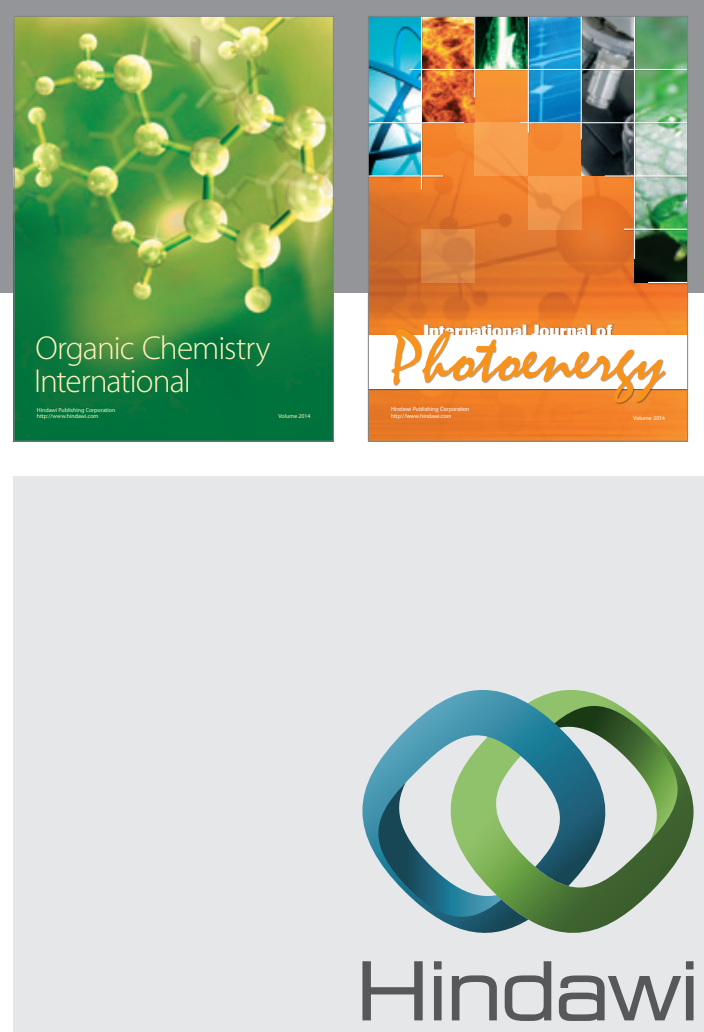

Submit your manuscripts at

http://www.hindawi.com

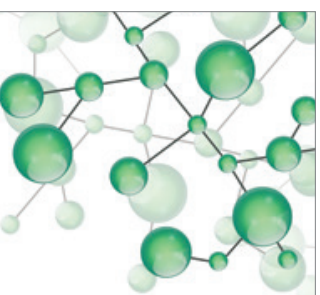

International Journal of

Inorganic Chemistry

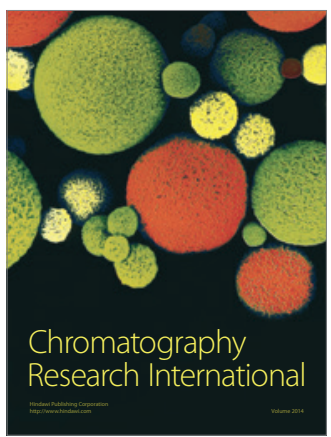

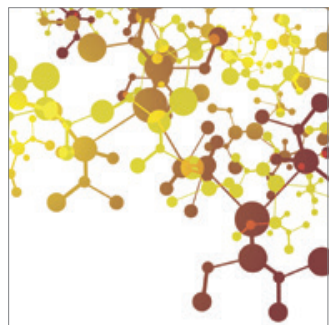

Applied Chemistry
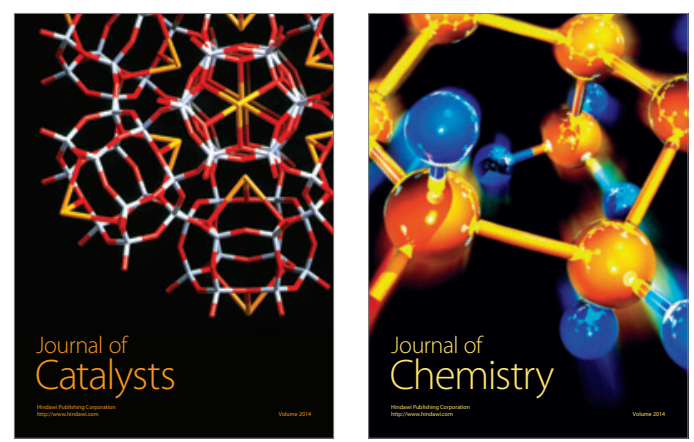
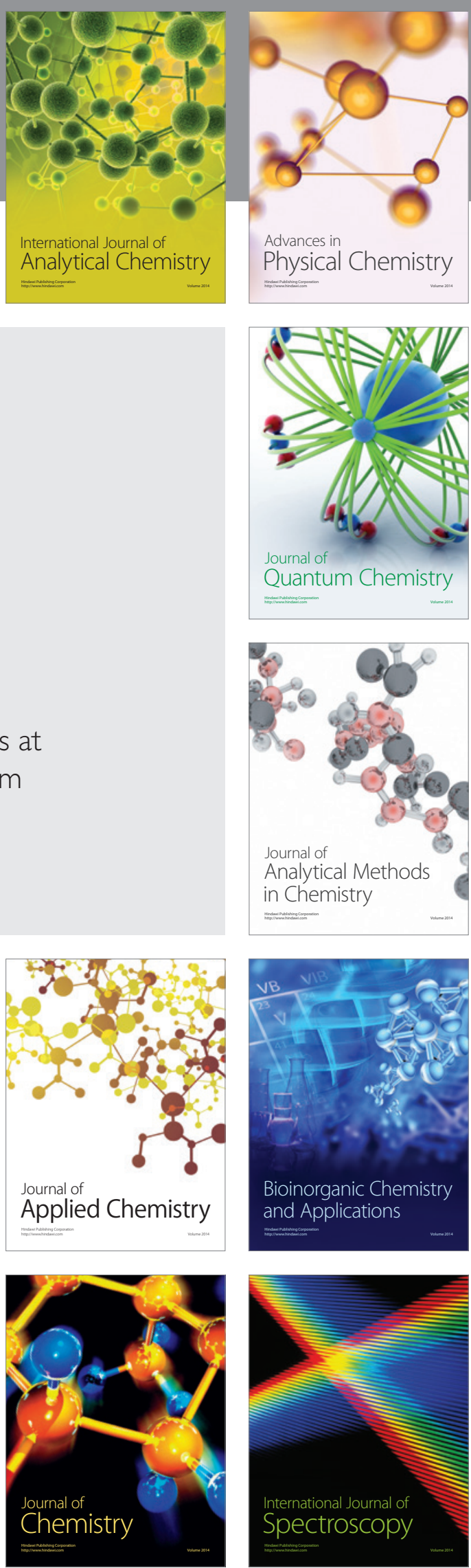